\title{
Predicted extracapsular invasion of hilar lymph node metastasis by fusion positron emission tomography/computed tomography in patients with lung cancer
}

\author{
TAKASHI MAKINO ${ }^{1}$, YOSHINOBU HATA ${ }^{1}$, HAJIME OTSUKA ${ }^{1}$, SATOSHI KOEZUKA ${ }^{1}$, \\ KAZUTOSHI ISOBE ${ }^{2}$, NOBUMI TOCHIGI ${ }^{3}$, NOBUYUKI SHIRAGA ${ }^{4}$, \\ KAZUTOSHI SHIBUYA ${ }^{3}$, SAKAE HOMMA ${ }^{2}$ and AKIRA IYODA ${ }^{1}$ \\ Divisions of ${ }^{1}$ Chest Surgery and ${ }^{2}$ Respiratory Medicine; Departments of ${ }^{3}$ Surgical Pathology \\ and ${ }^{4}$ Radiology, Toho University School of Medicine, Tokyo 143-8541, Japan
}

Received March 6, 2015; Accepted June 11, 2015

DOI: $10.3892 / \mathrm{mco} .2015 .596$

\begin{abstract}
Intraoperative detection of hilar lymph node metastasis, particularly with extracapsular invasion, may affect the surgical procedure in patients with lung cancer, as the preoperative estimation of hilar lymph node metastasis is unsatisfactory. The aim of this study was to investigate whether fusion positron emission tomography/computed tomography (PET/CT) is able to predict extracapsular invasion of hilar lymph node metastasis. Between April, 2007 and April, 2013, 509 patients with primary lung cancer underwent surgical resection at our institution, among whom 28 patients exhibiting hilar lymph node metastasis (at stations 10 and 11) were enrolled in this study. A maximum lymph node standardized uptake value of $>2.5$ in PET scans was interpreted as positive. A total of 17 patients had positive preoperative PET/CT findings in their hilar lymph nodes, while the remaining 11 had negative findings. With regard to extracapsular nodal invasion, the PET/CT findings $(\mathrm{P}=0.0005)$ and the histological findings (squamous cell carcinoma, $\mathrm{P}=0.05$ ) were found to be significant predictors in the univariate analysis. In the multivariate analysis, the PET/CT findings were the only independent predictor $(\mathrm{P}=0.0004)$. The requirement for extensive pulmonary resection (sleeve lobectomy, bilobectomy or pneumonectomy) was significantly more frequent in the patient group with positive compared with the group with negative
\end{abstract}

Correspondence to: Professor Akira Iyoda, Division of Chest Surgery, Toho University School of Medicine, 6-11-1 Omori-Nishi, Ota-ku, Tokyo 143-8541, Japan

E-mail: aiyoda@med.toho-u.ac.jp

Abbreviations: NSCLC, non-small-cell lung cancer; FDG-PET, 2-deoxy-2-( $\left.{ }^{18} \mathrm{~F}\right)$ fluoro-D-glucose-positron emission tomography; CT, computed tomography; MRI, magnetic resonance imaging; SUV, standardized uptake value; IASLC, International Association for the Study of Lung Cancer; OS, overall survival

Key words: extracapsular invasion, hilar lymph node, 2-deoxy-2-( $\left({ }^{18} \mathrm{~F}\right)$ fluoro-D-glucose-positron emission tomography, lung cancer, surgery
PET/CT findings (76 vs. 9\%, respectively, $\mathrm{P}=0.01$ ). Therefore, the PET/CT findings in the hilar lymph nodes were useful for the prediction of extracapsular invasion and, consequently, for the estimation of possible extensive pulmonary resection.

\section{Introduction}

While accurate preoperative staging of mediastinal and hilar lymph nodes is essential in determining the treatment strategy for patients with non-small-cell lung cancer (NSCLC) $(1,2)$, the accuracy of a preoperative diagnosis for $\mathrm{N} 1$ disease is problematic. Clinically diagnosed N1 (cN1) patients have been reported to comprise $19-30 \%$ pathologically N0 (pN0), 44-47\% pN1 and $17-60 \%$ pN2-pN3 cases (3-5). Partly due to the high rate of occult $\mathrm{pN} 2$ patients, the $\mathrm{cN} 1$ cohort was associated with an unsatisfactory surgical prognosis. Furthermore, unexpected extracapsular invasion of the metastatic hilar lymph nodes often results in extensive surgical resection more often than standard lobectomy, such as pneumonectomy, bilobectomy, or lobectomy with bronchoplasty and angioplasty. Diagnostic clues for the preoperative prediction of extranodal invasion and subsequent extensive surgical resection may be useful in determining the treatment strategy in surgical candidates, particularly those with certain surgical risks or with poor cardiopulmonary reserve. Positron emission tomography (PET) with 2-deoxy-2- $\left({ }^{18} \mathrm{~F}\right)$ fluoro-D-glucose as a tracer $\left({ }^{18} \mathrm{~F}-\mathrm{FDG}\right.$-PET) was recently reported to be more effective in detecting tumor involvement of mediastinal and hilar lymph nodes compared with computed tomography (CT) (6-8). However, those reports did not refer to the correlation between the PET findings and the type of lymph node metastasis, i.e., intracapsular or extracapsular, and the required surgical procedure, which was standard lobectomy or an extended resection. The aim of this study was to investigate the ability of fusion PET/CT to predict extracapsular invasion of hilar lymph node metastasis.

\section{Patients and methods}

Patients. Between April, 2007 and April 2013, 509 consecutive patients with primary lung cancer underwent surgical 
Table I. Characteristics of the patients with hilar lymph node metastasis $(n=28)$.

\begin{tabular}{|c|c|}
\hline Characteristics & Number \\
\hline \multicolumn{2}{|l|}{ Age, years } \\
\hline Mean (range) & $68(44-81)$ \\
\hline \multicolumn{2}{|l|}{ Gender } \\
\hline Male & 20 \\
\hline Female & 8 \\
\hline \multicolumn{2}{|l|}{ Smoking habits } \\
\hline Non-smoker & 4 \\
\hline Current/former smoker & 24 \\
\hline \multicolumn{2}{|l|}{ Histology } \\
\hline Squamous cell carcinoma & 11 \\
\hline Adenocarcinoma & 12 \\
\hline Others $^{\mathrm{a}}$ & 5 \\
\hline \multicolumn{2}{|l|}{ Tumor location } \\
\hline Right & 13 \\
\hline Left & 15 \\
\hline \multicolumn{2}{|l|}{ Pathological T stage } \\
\hline $\mathrm{T} 1$ & 11 \\
\hline $\mathrm{T} 2$ & 14 \\
\hline $\mathrm{T} 3$ & 3 \\
\hline \multicolumn{2}{|l|}{ Surgical procedures } \\
\hline Lobectomy & 12 \\
\hline Lobectomy with bronchoplasty & 1 \\
\hline Lobectomy with vascular plasty & 1 \\
\hline Bilobectomy & 5 \\
\hline Pneumonectomy & 9 \\
\hline
\end{tabular}

${ }^{\text {aS }}$ mall-cell, adenosquamous, large-cell neuroendocrine and pleomorphic carcinomas.

resection at our institution. Among these patients, 28 with pathologically proven hilar lymph node metastasis (at stations 10 and 11), without mediastinal lymph node metastasis and without having received induction therapy, were retrospectively reviewed in this study. All the patients underwent chest and abdominal CT, brain magnetic resonance imaging (MRI) and PET/CT for clinical staging, and were pathologically diagnosed with hilar lymph node metastasis postoperatively. The following parameters were assessed from the medical records: patient gender, age, smoking habits, histological type, tumor location, tumor stage, surgical procedure and prognosis.

This study was reviewed and approved by the Institutional Review Board of Toho University (Tokyo, Japan).

Treatments and evaluation. The routine preoperative workup included pulmonary function tests, CT scans of the chest and abdomen, PET/CT, flexible bronchoscopy and brain MRI. To evaluate lymph node metastasis, enhanced chest CT and $\mathrm{PET} / \mathrm{CT}$ were performed. A team of experienced radiologists reviewed the integrated $\mathrm{PET/CT}$ images independently. A lymph node maximum standardized uptake value $\left(\mathrm{SUV}_{\max }\right)$
Table II. Characteristics of the metastatic hilar lymph nodes.

\begin{tabular}{lr}
\hline Variables & Number \\
\hline Pathological N1 station & 5 \\
10L & 0 \\
10R & 10 \\
11L & 13 \\
11R & \\
Extracapsular nodal invasion & 14 \\
Absent & 14 \\
Present & \\
Preoperative hilar lymph node & \\
PET/CT findings & 17 \\
Positive & 11 \\
Negative & \\
\hline
\end{tabular}

PET/CT, fusion positron emission tomography/computed tomography.

of $>2.5$ was interpreted as positive $(9,10)$. All integrated $\mathrm{PET} / \mathrm{CT}$ imaging was performed within 4 weeks of surgery. The surgical procedures included standard lobectomy or extensive pulmonary resection, such as bilobectomy, sleeve resection, or pneumonectomy. Systematic lymph node dissection was mandatory for all the patients in this study. Mediastinal lymph node dissection consisted of en bloc resection of all nodes at stations $2 \mathrm{R}, 4 \mathrm{R}, 7,8,9,10 \mathrm{R}$ and $11 \mathrm{R}$ for right-sided tumors, and at stations $4 \mathrm{~L}, 5,6,7,8,9,10 \mathrm{~L}$ and $11 \mathrm{~L}$ for left-sided tumors. The designation of dissected nodal status was based on the International Association for the Study of Lung Cancer (IASLC) lymph node map (11) and the seventh edition of the TNM staging system (12). The histological classification of NSCLC was based on the WHO classification. The dissected lymph nodes were histologically examined using hematoxylin and eosin staining.

Statistical analysis. Univariate data analysis was conducted using Pearson's Chi-squared test and multivariate analysis was conducted using logistic regression (backward stepwise). Differences were considered to be statistically significant when $\mathrm{P}<0.05$. Overall survival (OS) was defined as the time from the date of surgery until the date of the last follow-up or death. Disease-specific survival was defined as the time from the date of surgery until the date of the last follow-up. Patients who remained alive or who had succumbed to a cause other than lung cancer, were censored for disease-specific survival analysis. Survival curves were prepared using the Kaplan-Meier method and were compared univariately using the log-rank test. All the statistical analyses were performed using JMP 11.0 software (SAS Institute Inc., Cary, NC, USA).

\section{Results}

Patient characteristics. The 28 patients with hilar lymph node metastasis were predominantly male $(71 \%)$ and smokers (86\%). The most common tumor types were squamous cell carcinoma in $11(39 \%)$ and adenocarcinoma in 
Table III. Univariate analysis for factors associated with PET/CT findings in hilar lymph node metastasis.

\begin{tabular}{|c|c|c|c|}
\hline \multirow[b]{2}{*}{ Variables } & \multicolumn{2}{|c|}{$\begin{array}{l}\text { Hilar lymph node } \\
\text { PET/CT findings }\end{array}$} & \multirow[b]{2}{*}{ P-value } \\
\hline & Positive & Negative & \\
\hline Mean age, years & 69 & 66.5 & 0.47 \\
\hline Gender & & & 0.11 \\
\hline Male & 14 & 6 & \\
\hline Female & 3 & 5 & \\
\hline Smoking habits & & & 0.12 \\
\hline Non-smoker & 1 & 3 & \\
\hline Current/former smoker & 16 & 8 & \\
\hline Tumor location & & & 0.93 \\
\hline Right & 9 & 6 & \\
\hline Left & 8 & 5 & \\
\hline Pathological T stage & & & 0.59 \\
\hline $\mathrm{T} 1$ & 6 & 5 & \\
\hline $\mathrm{T} 2-3$ & 11 & 6 & \\
\hline Pathological N1 station & & & 0.29 \\
\hline No. 10 & 2 & 3 & \\
\hline No. 11 & 15 & 8 & \\
\hline Histology & & & 0.29 \\
\hline Non-SCC & 9 & 8 & \\
\hline $\mathrm{SCC}$ & 8 & 3 & \\
\hline Extracapsular invasion & & & 0.001 \\
\hline Present & 13 & 1 & \\
\hline Absent & 4 & 10 & \\
\hline Surgical procedures & & & 0.01 \\
\hline Lobectomy & 4 & 8 & \\
\hline $\begin{array}{l}\text { Extensive pulmonary } \\
\text { resection }^{\mathrm{a}}\end{array}$ & 13 & 3 & \\
\hline
\end{tabular}

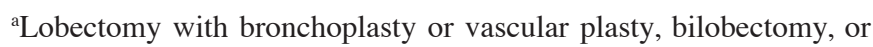
pnemonectomy. PET/CT, fusion positron emission tomography/computed tomography; SCC, squamous cell carcinoma.

12 patients (43\%). The surgical procedures performed were standard lobectomy in $12(43 \%)$ and extensive pulmonary resection in 16 patients $(57 \%)$. Of the patients receiving extensive pulmonary resection, 2 underwent plasty of the bronchus or pulmonary artery (Table I).

Characteristics of hilar lymph nodes. The metastatic N1 station was station 10 in $5(18 \%)$ and station 11 in 23 patients $(82 \%)$. Extracapsular invasion of the hilar lymph node was detected in 14 patients $(50 \%)$ (Table II).

PET/CT visual assessment analysis. A total of 17 patients (60\%) had positive hilar lymph node findings on PET/CT and the remaining 11 had negative findings (Table III). The rate of extracapsular invasion was significantly higher in the patient group with positive PET/CT findings (13/17, 76\%) compared
Table IV. Univariate analysis for factors predictive of extracapsular nodal invasion.

\begin{tabular}{|c|c|c|c|}
\hline \multirow[b]{2}{*}{ Variables } & \multicolumn{3}{|c|}{ Extracapsular nodal invasion } \\
\hline & HR & $95 \% \mathrm{CI}$ & P-value ${ }^{a}$ \\
\hline \multicolumn{4}{|l|}{ Age, years } \\
\hline$<70$ & 1 & & \\
\hline$\geq 70$ & 0.42 & $0.09-1.91$ & 0.25 \\
\hline \multicolumn{4}{|l|}{ Gender } \\
\hline Female & 1 & & \\
\hline Male & 2.03 & $0.38-10.9$ & 0.4 \\
\hline \multicolumn{4}{|l|}{ Smoking habits } \\
\hline Non-smoker & 1 & & \\
\hline Current/former smoker & 3.5 & $0.32-39.1$ & 0.28 \\
\hline \multicolumn{4}{|l|}{ Tumor location } \\
\hline Right & 1 & & \\
\hline Left & 1.33 & $0.30-5.91$ & 0.14 \\
\hline \multicolumn{4}{|l|}{$\begin{array}{l}\text { Hilar lymph node } \\
\text { PET/CT findings }\end{array}$} \\
\hline Negative & 1 & & \\
\hline Positive & 32.5 & $3.12-337$ & 0.0005 \\
\hline \multicolumn{4}{|l|}{ Pathological T stage } \\
\hline $\mathrm{T} 1$ & 1 & & \\
\hline $\mathrm{T} 2-3$ & 1.35 & $0.29-6.18$ & 0.7 \\
\hline \multicolumn{4}{|l|}{ Pathological N1 station } \\
\hline No. 10 & 1 & & \\
\hline No. 11 & 1.64 & $0.23-11.7$ & 0.62 \\
\hline \multicolumn{4}{|l|}{ Histology } \\
\hline Non-SCC & 1 & & \\
\hline $\mathrm{SCC}$ & 4.88 & $0.93-25.6$ & 0.05 \\
\hline
\end{tabular}

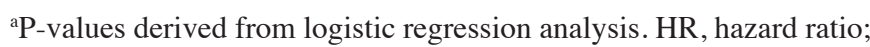
CI, confidence interval; PET/CT, fusion positron emission tomography/computed tomography; SCC, squamous cell carcinoma.

with that in the group with negative PET/CT findings $(1 / 11,9 \%)$ $(\mathrm{P}=0.0005)$. Extensive pulmonary resection was performed more frequently in the patient group with positive PET/CT findings $(13 / 17,76 \%)$ compared with the group with negative PET/CT findings $(3 / 11,27 \%)(\mathrm{P}=0.01)$.

Analysis of extracapsular invasion of hilar lymph nodes. The univariate analysis identified two factors as significant predictors of extracapsular nodal invasion, namely the PET/CT and histological findings $(\mathrm{P}=0.0005$ and 0.05 , respectively) (Table IV). In the multivariate analysis, the PET/CT findings were the only independent predictor $(\mathrm{P}=0.0004)$ (Table V).

Survival pattern analysis. A total of 3 patients (11\%) succumbed during the postoperative period (pneumonia, 2 patients; and acute exacerbation of interstitial pneumonia, 1 patient). Follow-up was performed for all the patients. The median follow-up time was 39.5 months (range, 0-80 months). The 5-year OS rate was 82 vs. $38 \%$ in the patient groups with positive vs. negative 
Table V. Multivariate analysis for factors predictive of extracapsular nodal invasion.

\begin{tabular}{lccc}
\hline Variables & HR & $95 \%$ CI & P-value $^{\text {a }}$ \\
\hline $\begin{array}{l}\text { PET/CT findings } \\
\text { Negative }\end{array}$ & 1 & & \\
$\begin{array}{l}\text { Positive } \\
\text { Histology } \\
\text { Non-SCC }\end{array}$ & 39 & $4.2-1217$ & 0.0004 \\
SCC & 1 & & \\
\hline $\begin{array}{l}\text { aP-value derived from logistic regression analysis. HR, hazard ratio; } \\
\text { CI, confidence interval; PET/CT, fusion positron emission tomog- } \\
\text { raphy/computed tomography; SCC, squamous cell carcinoma. }\end{array}$
\end{tabular}

PET/CT findings, respectively (Fig. 1). The difference between the two groups was not statistically significant $(\mathrm{P}=0.123)$. The 5-year disease-specific survival rate was 100 vs. $50 \%$ in the patient groups with positive vs. negative PET/CT findings, respectively (Fig. 2). The difference between the two groups was not statistically significant $(\mathrm{P}=0.055)$, although the group with positive $\mathrm{PET} / \mathrm{CT}$ findings tended to have a better prognosis compared with the group with negative findings.

\section{Discussion}

The presence of pN1 disease may unavoidably lead to changes in the surgical approach. A recent study reported that extensive pulmonary resection was required in $41 \%$ of patients with $\mathrm{cN} 1$ disease. Therefore, it is crucial to predict the potential extracapsular invasion of hilar lymph node metastasis preoperatively. The main findings of the present study were as follows: i) PET/CT was a significant predictor of extracapsular invasion in cases with hilar lymph node metastasis and ii) extensive pulmonary resection was required in $76 \%$ of the patients with positive hilar lymph node metastasis on PET/CT.

$\mathrm{PET} / \mathrm{CT}$ is most beneficial for identifying the presence of metastatic disease. PET/CT relies on the hypermetabolic nature of cancer cells for preferential uptake of the radiolabeled glucose analogue ${ }^{18} \mathrm{~F}-\mathrm{FDG}$. The fusion of PET and CT simultaneously provides anatomical and functional information, thus improving localization accuracy. Preferential uptake of ${ }^{18} \mathrm{~F}$-FDG in the lymph nodes may be quantified by the SUV. In the mediastinum, high SUV cut-off values identifying malignant lymph nodes increase the chances of false-negative results, thus leading to the current recommendation of an SUV of 2.5 as the criterion for the classification of a node as positive $(9,13)$. Using an SUV of 2.5 as the threshold, the resulting sensitivity, specificity and negative predictive value were reported to be 89,84 and $96 \%$, respectively (9).

Imaging tests, such as PET-CT, have been used for the clinical diagnosis of the nodal status during staging. Previous randomized trials have demonstrated that PET/CT is significantly more accurate and more sensitive for the staging of NSCLC compared with the conventional staging regimen (14). The pooled sensitivity and specificity of PET for identifying mediastinal lymph node metastasis were reported to be

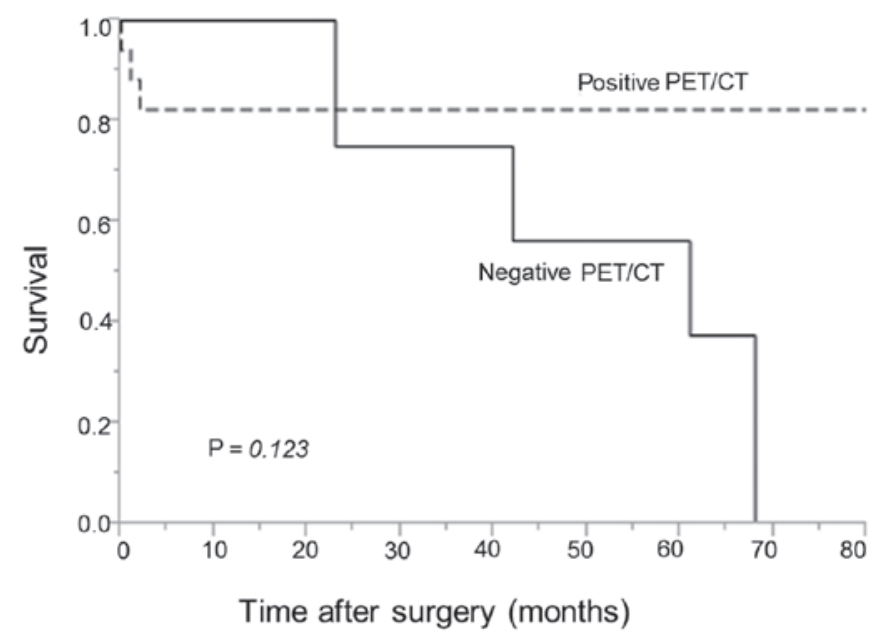

Figure 1 . The 5 -year overall survival rate was 82 vs. $38 \%$ in the patients with positive vs. negative hilar lymph node findings on PET/CT, respectively. There was no significant difference between the two groups $(\mathrm{P}=0.123)$. $\mathrm{PET} / \mathrm{CT}$, fusion positron emission tomography/computed tomography.

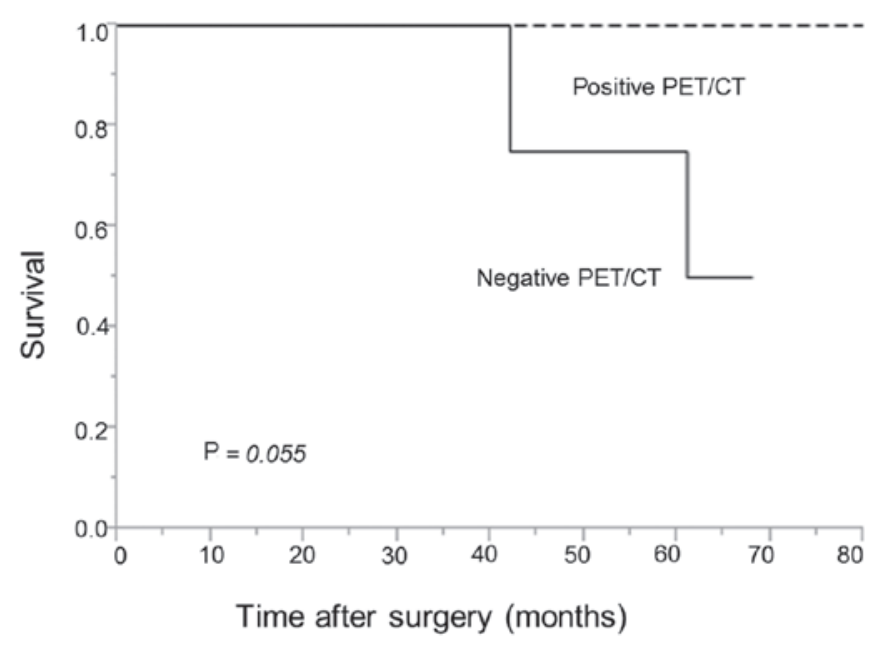

Figure 2. The 5-year disease-specific survival rate was 100 vs. $50 \%$ in the patients with positive vs. negative hilar lymph node findings on PET/CT, respectively. The patients with positive PET/CT findings tended to have a better prognosis $(\mathrm{P}=0.055)$. $\mathrm{PET} / \mathrm{CT}$, fusion positron emission tomography/computed tomography.

74 and $85 \%$, respectively (15). However, the sensitivity and specificity of PET for identifying hilar lymph node metastasis were only 48.5 and $80.2 \%$, respectively (10). Furthermore, it is more difficult to discriminate N1 involvement and primary tumors per se using imaging alone, particularly when the primary tumor is very close in proximity to the N1 nodes involved. Therefore, tissue confirmation is recommended to determine whether lymph node metastasis is truly present. Hilar lymph nodes have recently become accessible by means of endobronchial ultrasound (16). However, extracapsular invasion of hilar lymph node metastasis is difficult to diagnose using endobronchial ultrasound.

The present study identified PET/CT as a significant predictor of extracapsular invasion of hilar lymph node metastasis in the multivariate analysis $(\mathrm{P}=0.0005)$. Shin et al (17) reported that the presence of extracapsular nodal invasion 
detected by both $\mathrm{CT}$ and PET/CT was more frequent in the cN1-pN1 group compared with the cN0-pN1 group, resulting in a poorer surgical outcome. Although PET/CT is reported to be less sensitive for identifying hilar lymph node metastasis, we found it to be useful for identifying extracapsular invasion of hilar lymph node metastasis.

Regarding surgery, Watanabe et al (3) reported that extensive pulmonary resection was required in $41 \%$ of patients with $\mathrm{cN} 1$ disease. Moreno et al (18) reported that pneumonectomy was required in $40 \%$ of surgically treated $\mathrm{T} 3_{>7 \mathrm{~cm}}$ N1 NSCLC patients. The postoperative mortality rate for surgical resections in lung cancer was recently found to have significantly improved (19); thus, preoperative detailed cardiopulmonary function tests should be mandatory to reduce surgical morbidity and mortality. In the present study, extensive pulmonary resection was required in $53 \%$ of the patients with hilar lymph node metastasis. Furthermore, extensive pulmonary resection was required in $76 \%$ of the patients with positive hilar lymph node metastasis on PET/CT $(\mathrm{P}=0.003)$. It may be deduced from our findings that such patients are more likely to require extensive pulmonary resection, as hilar lymph node metastasis with extracapsular invasion is very close in proximity to the bronchus and pulmonary arteries.

As regards prognosis, there was no significant difference in OS or disease-specific survival rates between the positive and negative PET/CT groups in our study. However, the positive $\mathrm{PET} / \mathrm{CT}$ group tended to have a better prognosis in terms of disease-specific survival $(\mathrm{P}=0.055)$, exhibiting a $100 \%$ disease-specific survival rate at 5 years. The positive PET/CT group displayed a high rate of extracapsular invasion (76\%) and required extended surgical resection. While the presence of extracapsular invasion may indicate poor survival (17), the positive PET/CT group exhibited favorable outcomes, probably due to the beneficial effect of extended surgical resection on curability. Even with extracapsular involvement, sufficient therapy by extensive surgical resection may result in an acceptable surgical outcome. Preoperative meticulous evaluation of pulmonary and cardiac function tests should be mandatory for patients with positive hilar lymph node findings on PET/CT to assess the possibility of extended resection.

This study had several limitations. As our data were retrospectively collected and reviewed, there were some intrinsic drawbacks. In addition, although all the patients had pN1 disease, the study population comprised a heterogeneous group of subjects. In this study, the CT size criterion for metastatic lymph nodes, i.e., a short-axis diameter of $>1 \mathrm{~cm}$ on a transverse CT image, was not implemented, the reason being that the hilar lymph nodes were difficult to distinguish from blood vessels in certain patients examined without the use of intravenous contrast medium.

In conclusion, we retrospectively reviewed the clinical and pathological characteristics of patients with hilar lymph node metastasis following surgical resection for NSCLC. The PET/CT findings were a significant predictor of extracapsular invasion of hilar lymph node metastasis. Extensive pulmonary resection was required in patients with positive hilar lymph node metastasis on PET/CT, resulting in acceptable surgical outcomes, despite a relatively high postoperative mortality rate. Thus, meticulous preoperative evaluation of pulmonary and cardiac function test should be mandatory for patients with
PET/CT positive hilar lymph node for determining potential extensive pulmonary resection.

\section{Acknowledgements}

This study was supported in part by a Grant-in-aid for Scientific Research (C) 24592098 and 26462140 from the Japanese Ministry of Education, Culture, Sports, Science and Technology.

\section{References}

1. Mountain CF: Revisions in the international system for staging lung cancer. Chest 111: 1710-1717, 1997.

2. Rusch VW, Crowley J, Giroux DJ and Goldstraw P, Im JG, Tsuboi M, Tsuchiya R and Vansteenkiste J; International Staging Committee; Cancer Research and Biostatistics; Observers to the Committee; Participating Institutions: The IASLC Lung Cancer Staging Project: proposals for the revision of the N descriptors in the forthcoming seventh edition of the TNM classification for lung cancer. J Thorac Oncol 2: 603-612, 2007.

3. Watanabe S, Asamura H, Suzuki K and Tsuchiya R: Problems in diagnosis and surgical management of clinical N1 non-small cell lung cancer. Ann Thorac Surg 79: 1682-1685, 2005.

4. Hishida T, Yoshida J, Nishimura M, Nishiwaki Y and Nagai K: Problems in the current diagnostic standards of clinical N1 non-small cell lung cancer. Thorax 63: 526-531, 2008.

5. Miyasaka Y, Suzuki K, Takamochi K, Matsunaga T and Oh S: The maximum standardized uptake value of fluorodeoxyglucose positron emission tomography of the primary tumour is a good predictor of pathological nodal involvement in clinical N0 non-small-cell lung cancer. Eur J Cardiothorac Surg 44: 83-87, 2013.

6. Steinert HC, Hauser M, Allemann F, Engel H, Berthold T, von Schulthess GK and Weder W: Non-small cell lung cancer: Nodal staging with FDG PET versus CT with correlative lymph node mapping and sampling. Radiology 202: 441-446, 1997.

7. Vansteenkiste JF, Stroobants SG, De Leyn PR, Dupont PJ, Verschakelen JA, Nackaerts KL and Mortelmans LA; Leuven Lung Cancer Group: Mediastinal lymph node staging with FDG-PET scan in patients with potentially operable non-small cell lung cancer: A prospective analysis of 50 cases. Chest 112: 1480-1486, 1997.

8. Vansteenkiste JF, Stroobants SG, Dupont PJ, De Leyn PR, De Wever WF, Verbeken EK, Nuyts JL, Maes FP and Bogaert JG: FDG-PET scan in potentially operable non-small cell lung cancer: Do anatometabolic PET-CT fusion images improve the localisation of regional lymph node metastases? The Leuven Lung Cancer Group. Eur J Nucl Med 25: 1495-1501, 1998.

9. Hellwig D, Graeter TP, Ukena D, Groeschel A, Sybrecht GW, Schaefers HJ and Kirsch CM: ${ }^{18} \mathrm{~F}-\mathrm{FDG}$ PET for mediastinal staging of lung cancer: Which SUV threshold makes sense? J Nucl Med 48: 1761-1766, 2007.

10. Carrillo SA, Daniel VC, Hall N, Hitchcock CL, Ross P Jr and Kassis ES: Fusion positron emission/computed tomography underestimates the presence of hilar nodal metastases in patients with resected non-small cell lung cancer. Ann Thorac Surg 93: 1621-1624, 2012.

11. Rusch VW, Asamura H, Watanabe H, Giroux DJ, Rami-Porta R and Goldstraw P; Members of IASLC Staging Committee: The IASLC Lung Cancer Staging Project: a proposal for a new international lymph node map in the forthcoming seventh edition of the TNM classification for lung cancer. J Thorac Oncol 4: 568-577, 2009.

12. Detterbeck FC, Boffa DJ and Tanoue LT: The new lung cancer staging system. Chest 136: 260-271, 2009.

13. Vansteenkiste JF, Stroobants SG, Dupont PJ, De Leyn PR, Verbeken EK, Deneffe GJ, Mortelmans LA and Demedts MG; Leuven Lung Cancer Group: Prognostic importance of the standardized uptake value on ${ }^{18} \mathrm{~F}$-fluoro-2-deoxy-glucose-positron emission tomography scan in non-small-cell lung cancer: An analysis of 125 cases. J Clin Oncol 17: 3201-3206, 1999.

14. Fischer B, Lassen U, Mortensen J, Larsen S, Loft A, Bertelsen A, Ravn J, Clementsen P, Høgholm A, Larsen K, et al : Preoperative staging of lung cancer with combined PET-CT. N Engl J Med 361: 32-39, 2009. 
15. Silvestri GA, Gould MK, Margolis ML, Tanoue LT, McCrory D, Toloza E and Detterbeck F; American College of Chest Physicians: Noninvasive staging of non-small cell lung cancer: ACCP evidenced-based clinical practice guidelines (2nd edition). Chest 132 (Suppl 3): 178S-201S, 2007.

16. Ernst A, Eberhardt R, Krasnik M and Herth FJ: Efficacy of endobronchial ultrasound-guided transbronchial needle aspiration of hilar lymph nodes for diagnosing and staging cancer. J Thorac Oncol 4: 947-950, 2009.

17. Shin S, Kim HK, Choi YS, Kim K, Kim J and Shim YM: Prognosis of unexpected and expected pathologic N1 non-small cell lung cancer. Ann Thorac Surg 96: 969-975, discussion 975-976, 2013
18. Moreno AC, Morgensztern D, Boffa DJ, Decker RH, Yu JB, Detterbeck FC, Wang Z, Rose MG and Kim AW: Treating locally advanced disease: An analysis of very large, hilar lymph node positive non-small cell lung cancer using the National Cancer Data Base. Ann Thorac Surg 97: 1149-1155, 2014.

19. Watanabe S, Asamura H, Suzuki K and Tsuchiya R: Recent results of postoperative mortality for surgical resections in lung cancer. Ann Thorac Surg 78: 999-1002, discussion 1002-1003, 2004. 